\title{
Economic Analysis of Feeding Synbiotic to Jersey Crossbred Calves
}

\author{
Jyotimala Sahu $^{1 *}$, Saroj Rai ${ }^{2}$, Rajlaxmi Behera ${ }^{3}$, Tripti Kumari ${ }^{2}$, \\ D.K. Mandal ${ }^{2}$ and Aayush Yadav \\ ${ }^{1}$ Department of Livestock Production and Management, ICAR-National Dairy Research \\ Institute, Karnal-132001, Haryana, India \\ ${ }^{2}$ Department of Livestock Production and Management, ICAR, ERS-National Dairy Research \\ Institute, Kalyani-741235, West Bengal, India \\ ${ }^{3}$ Department of Animal Genetics and Breeding, ICAR, ERS-National Dairy Research Institute, \\ Kalyani-741235, West Bengal, India \\ ${ }^{4}$ Department of Livestock Production Management, College of Veterinary Science \& A.H., \\ CGKV, Anjora, Durg, Chhattisgarh, India \\ *Corresponding author
}

\section{A B S T R A C T}

Keywords

Synbiotic,

Lactobacillus

rhamnosus, Calf,

Feeding, Economics

Article Info

Accepted:

22 October 2019

Available Online:

10 November 2019
The present study was conducted with an objective to evaluate the effect of synbiotic (Lactobacillus rhamnosus NCDC298 and Fructo-oligosaccharide) supplementation on growth performance (Dry matter intake, body weight gain, body measurement) and economic efficiency in Jersey crossbred calves. The experimental calves were divided in two groups with an average body weight (kg) of $23.42 \pm 1.91$ and $23.17 \pm 1.19$ in the treatment and control group respectively. The experimental trial was for 90 days and synbiotic feeding trial to the treatment was conducted for 45 days period. The results revealed that supplementing synbiotic to Jersey crossbred calves has no significant effect on dry matter intake and body measurements. Total body weight gain $(\mathrm{kg})$ in 90 days was significantly $(\mathrm{P}<0.01)$ improved in synbiotic fed group as compared to control group $(29.08 \pm 0.90$ vs $23.58 \pm 2.38)$. Average daily gain was significantly higher in the Treatment group $(323.14 \pm 0.01 \mathrm{~g})$ when compared to the calves in control group $(262.03 \pm 0.03 \mathrm{~g})$. Feed cost per $\mathrm{kg}$ body weight gain was reduced by Rs. 24.70 in treatment group in comparison to control group (Rs. 243.53 vs Rs. 268.23).

\section{Introduction}

Calves are prone to many disease-producing organisms and nutritional issues at an initial stage of their life. For many years, these problems were encountered by the use of antibiotics which further added to the economic benefits in terms of enhanced performances of calves and reduced medication expenses. Meanwhile, the 
excessive utilization of antibiotics has increased the chances of antibiotic resistance in microorganisms. This has raised the questions to the experts in the field of animal husbandry towards the utilization of antibiotics. During the last decade, the equilibrium in the microbial flora of intestine has been considered as the potent factor to be manipulated to obtain higher growth performance in dairy calves. Probiotics are live micro-organisms that provide health benefits to the host (FAO/ WHO, 2002) and are known as a good alternative for manipulation of gut microbiota. Alternatively, prebiotics are non-digestible food ingredients that stimulate and nourish the growth of good bacteria already present in the intestine (Gaggiaet al., 2010). Prebiotic is synergistic with probiotic; combination in called as synbiotic, having a systemic effect on utilization of feed ingredient, stimulation of immunity and neutralization of toxins and they exert their action by lowering $\mathrm{pH}$ through lactic acid production and thus inhibit colonization of pathogenic bacteria (Simmering and Blaut, 2001; Patterson and Burkholder, 2003). The cost of antibiotics is generally seen as low than most of the alternatives (Kirwan and Kemin, 2017). Although, they are relatively cheap, reliable, and easy to use in the longer term they bring economic risks while probiotics are economically viable in terms of better growth and performance and this results in the most profitable analysis (Lokapirnasar et al., 2017).

\section{Materials and Methods}

\section{Place of work and experimental animal}

The present study was carried out at ICARNational Dairy Research Institute (NDRI), Eastern Regional Station, Kalyani, West Bengal. Twelve healthy Jersey crossbred calves were selected randomly for the study from the Institute cattle yard and divided into
2 groups; treatment $(\mathrm{T})$ and control $(\mathrm{C})$ group consisting of 6 calves each. Calves were separated from their mother immediately after calving. Average birth weight $(\mathrm{kg})$ was $23.42 \pm 1.91$ and $23.17 \pm 1.19$ in the treatment and control group respectively. Male to female ratio was maintained at $2: 1$.

\section{Feeding Practice}

All calves received colostrum and milk through bottle feeding. Colostrum was fed within one hour of birth followed by a second dose after 10-12 hour and fed up to 3 days. Milkwas fed @ $1 / 10^{\text {th }}$ of body weight up to 2 months then @ $1 / 20^{\text {th }}$ from 3rd month onwards in divided doses; morning (08.00 hour) and evening (16.00 hour). In the treatment group, synbiotic was offered with milk for 42 days @ $100 \mathrm{ml} /$ day/animal in two divided doses. All the calves in both the group received ad libitum supply of concentrates, green fodder and water throughout the experimental period. The experiment was continued up to age of 90 days.

\section{Preparation of Synbiotic}

Lactobacillus rhamnosus NCDC298 was procured from National Collection of Dairy Culture, Microbiology division, National Dairy Research Institute, Karnal (Haryana). It was activated in $10 \mathrm{ml}$ skimmed milk and incubated for 12-16 hour. This activated bacteria was further sub-cultured in $10 \mathrm{ml}$ skimmed milk for 12-16 hour. Fructooligosaccharide was added in milk @10\% and the subculture containing Lactobacillus rhamnosus NCDC298 was added and incubated for 12-16 hour.

\section{Parameters recorded}

Growth performance of the calves was measured by recording dry matter intake, body weight gain and body measurements. Dry 
matter of colostrum, milk, concentrate and fodders offered were calculated on weekly basis. Dry matter content of Colostrum, milk, concentrate and fodder sample was taken in hot air oven at $100 \pm 2^{\circ} \mathrm{C}$ for 24 hour and calculated (AOAC, 2005) as follows;

Dry matter $(\%)$

Dry weight of sample $(\mathrm{g})$

Fresh weight of sample (g)

Total intake was calculated by subtracting the residue from the initial feed supplied to the calves. Body weight $(\mathrm{kg})$ of calves was taken at weekly intervals before offering feed in the mornings. Body measurement $(\mathrm{cm})$ including body length, heart girth and wither height was taken at weekly intervals from birth to 90 days age. Economics of feeding was calculated on the basis of variable feeding costs.

\section{Statistical analysis}

Analysis of variance (ANOVA) was carried out to analyze the data using SPSS Ver. 20.

\section{Results and Discussion}

\section{Growth performance}

Calves belonging to synbiotic group had significantly better growth performance with higher body weight, average daily weight gain when compared to the control group. The results regarding growth performance are presented in Table 1. The dry matter intake showed no significant difference in control and treatment groups and the value was in close correspondence to the findings of Adangaleet al., (2009) in crossbred calves. This may be due to similar feeding and management condition of the experimental calves though DMI was expected to be higher in the treatment group. Similarly Cruywagen et al., (1996) fed Lactobacillus acidophilus to
Holstein calves and found no significant effects of Lactobacillus on dry matter intake of calves. Higginbotham et al., (1998) found similar results on the calves supplemented lactic acid bacteria in milk replacer. Similarly Sun et al., (2010); Riddell et al., (2010); Kawakami et al., (2010); Quezada-Mendoza et al., (2011) and Zhang et al., (2015) reported no significant effects on dry matter intake after supplementation of probiotics to the calves.

It is observed that there is significant difference $(\mathrm{P}<0.05)$ in the weight gain between the groups. The total body weight gain $(\mathrm{kg})$ in 90 days was significantly higher $(29.08 \pm 0.90)$ in the treatment group as compared to control group $(23.58 \pm 2.38)$ i.e. the effect of synbiotic feeding on weight gain of the crossbred calves. Average daily gain was significantly higher in the Treatment group $(323.14 \pm 0.01 \mathrm{~g})$ when compared to the calves in control group $(262.03 \pm 0.03 g)$. Such increase in body weights due to synbiotic supplements have also been reported by Hasunumaet al., (2011) and Dar et al., (2017). In addition to synbiotics, significant improvement in the body weight and average daily gain in the calves were observed by the utilization of probiotics such as L. plantarum and L. acidophilus (Gupta et al., 2016), L. sporogenes and $S$. cerevisiae (Nageshwar et al., 2016), etc. have recorded significant increase in body weight gain and average daily gain in the calves. As per, Dar et al., (2017) and Nageshwar et al., (2016) such increase in body weight gain due to probiotic and synbiotic use may be due to better intestinal microbial balance leading to efficient digestion and absorption of nutrients from the gastrointestinal tract.

With respect to body measurements, no significant differences have been found between groups though the synbiotic supplemented calves had higher gains in the 
respective body measurements. Nageshwar $e t$ al., (2016) found numerically higher body measurements including body length, heart girth and height in the calves supplemented with probiotics as compared to control group but the differences were not significant between the groups. Similarly Heinrichs et al., (2009) and Riddell et al., (2010) did not found any effect on heart girth, hip width and wither height in the calves fed commercial probiotics. Likewise Windschitl et al., (1991) fed mixture of probiotics to the calves and observed statistically no significant differences for wither height and heart girth between the groups while higher heart girth was noted in the treated calves.

\section{Economics of feeding synbiotic}

The attributes for estimation of economic analysis for both groups have been presented in Table 2. Perusal of the table revealed that total feeding cost per calf per day was Rs. 77.61 and Rs. 81.54 in the control and synbiotic supplemented group respectively. Higher feeding cost in the treatment group was due to the processing cost of synbiotic (Rs. 7.6/calf/day). The average daily gain in body weight in the treatment group was 61.11 g higher in comparison to the control group (323.14g in treatment vs $262.03 \mathrm{~g}$ in control group). Furthermore, feed cost per $\mathrm{kg}$ body weight gain was reduced by Rs. 24.70 in treatment group in comparison to control group (Rs. 243.53 in treatment vs Rs. 268.23 in control group). It is found that feed cost $/ \mathrm{kg}$ live weight gain was lowered by $9.2 \%$ in the treatment groups compared to control. Fixed cost has not been taken into consideration as the experimental conditions are the same in control and experimental group. Nageshwar $e t$ al., (2016) reported less feed cost $/ \mathrm{kg}$ live weight gain by 10.2 and $10.5 \%$ in the treatment groups compared to control group when supplemented combination of the same probiotic @ 5 and 10g respectively to Kankrej calves. Whereas Gupta et al., (2016) found lower feed cost per kg weight gain in group of calves supplemented with probiotic however total cost of feeding was almost similar in the treatment (Rs. 2281.13 and 2278.82) and control group (Rs. 2278.82). Dar et al., (2017) investigated that calves reared on probiotic and synbiotic supplement had reduced cost $/ \mathrm{kg}$ weight gain Rs. 5.20 and 6.68 respectively than the calves received common supplement.

Table.1 Mean \pm SE values for the growth performances of the calves in control and treatment groups

\begin{tabular}{|c|c|c|c|}
\hline S.N. & Parameters & Control & Treatment \\
\hline $\mathbf{1}$ & Total (milk + concentrate + green fodder) & $1.00 \pm 0.06$ & $1.04 \pm 0.07$ \\
\hline $\mathbf{2}$ & DMI (kg/animal/day) & & \\
\hline $\mathbf{3}$ & DMI/100 kg Body weight & $3.06 \pm 0.19$ & $3.01 \pm 0.16$ \\
\hline $\mathbf{4}$ & Total body weight gain in 90 days $(\mathrm{kg})$ & $23.58 \pm 2.38^{\mathrm{x}}$ & $29.08 \pm 0.90^{\mathrm{y}}$ \\
\hline $\mathbf{5}$ & Average daily gain in 90 days $(\mathrm{g})$ & $262.03 \pm 0.03^{\mathrm{x}}$ & $323.14 \pm 0.01^{\mathrm{y}}$ \\
\hline $\mathbf{6}$ & Body length $(\mathrm{cm})$ & $66.47 \pm 0.72$ & $66.48 \pm 0.82$ \\
\hline $\mathbf{7}$ & Heart girth $(\mathrm{cm})$ & $73.89 \pm 0.64$ & $75.47 \pm 0.72$ \\
\hline${ }^{\mathrm{xy}}$ Differences in superscript in row indicate significance at $P<0.05$ & $73.52 \pm 0.51$ & $73.54 \pm 0.61$ \\
\hline
\end{tabular}


Table.2 Economics of feeding of day old calf up to three months of age under different groups

\begin{tabular}{|c|c|c|c|}
\hline S.N. & Attributes & Control & Treatment \\
\hline $\mathbf{1 .}$ & Cost of milk consumed (Rs.) /animal/day & 59.41 & 59.80 \\
\hline $\mathbf{2}$ & Cost of concentrate consumed (Rs.) /animal/day & 8.53 & 8.80 \\
\hline $\mathbf{3}$ & Cost of green fodder consumed (Rs.) /animal/day & 1.81 & 1.73 \\
\hline $\mathbf{4}$ & Cost of synbiotic (Rs.)/animal/day & 0.00 & 7.60 \\
\hline $\mathbf{5}$ & Feed cost (Rs.) /animal/day & 69.75 & 77.93 \\
\hline $\mathbf{6}$ & Body weight gain/animal/day (g) & 262.03 & 323.14 \\
\hline $\mathbf{7}$ & Feed cost (Rs.) / kg gain in body weight & 268.23 & 243.53 \\
\hline
\end{tabular}

The study indicated improved growth performance and reduced feeding cost $/ \mathrm{kg}$ body weight gain. It is concluded that a combination of probiotic and prebiotic could provide better result and the potentiated probiotics are effective.

\section{Acknowledgement}

The authors would like to thank the Director of the ICAR-NDRI, Head of Eastern regional station, NDRI, technical staffs and assistants.

\section{References}

Association of official analytical chemists (AOAC). (2005). Official methods of analysis $18^{\text {th }}$ edition. Maryland. USA.

Adangale, S. B., Mitkari K R, Walkunde T R and Baswade S V. 2009. Effect of feeding Jowar straw in combination with soybean straw on the growth performance of crossbred heifer. Indian Journal of Animal Research 43(2): 142-144.

Cruywagen, C., Jordaan, I., and Venter, L. (1996). Effect of Lactobacillus acidophilus Supplementation of Milk Replacer on Preweaning Performance of Calves. Journal of Dairy Science 79(3): 483-486.

Dar, A., Singh, S., Palod, J., Ain, K., Kumar, N., Farooq, F. and Khadda, B. (2017). Effect of Probiotic, Prebiotic and Synbiotic on Hematological
Parameters of Crossbred

Calves. International Journal of Livestock Research 7(4): 128-136.

Gupta, P., Sharma, K. S. and Porwal, M. (2016). Nutrient balance and economics of young calves raised on Lactobacilli supplemented milk replacer. Veterinary Practitioner 17(2): 276-279.

Hasunuma, T., Kawashima, K., Nakayama, H., Murakami, T., Kanagawa, H., Ishii, T., and Kushibiki, S. (2011). Effect of cellooligosaccharide or synbiotic feeding on growth performance, fecal condition and hormone concentrations in Holstein calves. Animal science journal 82(4): 543-548.

Heinrichs, A. J., Jones, C. M., ElizondoSalazar, J. A., and Terrill, S. J. (2009). Effects of a prebiotic supplement on health of neonatal dairy calves. Livestock science 125(2): 149154.

Higginbotham, G. E., Robison, J. D., Atwill, E. R., Gracas, M. D., Pereira, C., Howes, A. D. and Males, J. R. (1998). Effect of a Direct-Fed Microbial Product on Calf Performance and Fecal Flora1. The Professional Animal Scientist 14(2): 108-113.

Kawakami, S. I., Yamada, T., Nakanishi, N. andCai, Y. (2010). Feeding of lactic acid bacteria and yeast on growth and diarrhea of Holstein calves. Journal of 
Animal and Veterinary Advances 9(7): 1112-1114.

Nageshwar,A., Raval, A. P., Bhagwat, S. R. and Rajgor, B. B. (2016). Studies on growth, nutrient utilization, immune modulation, and economic return at different levels of probiotic feed supplementation in Kankrej female calves. Animal Science 10(2): 55-62.

Quezada-Mendoza, V. C., Heinrichs, A. J. and Jones, C. M. (2011). The effects of a prebiotic supplement (Prebio Support) on fecal and salivary IgA in neonatal dairy calves. Livestock Science142(1): 222-228.

Riddell, J. B., Gallegos, A. J., Harmon, D. L. and McLeod, K. R. (2010). Addition of a Bacillus based probiotic to the diet of preruminant calves: Influence on growth, health, and blood parameters1, 2, 3. International Journal of Applied
Research in Veterinary Medicine 8(1): 78-85.

Sun, P., Wang, J. Q. and Zhang, H. T. (2010). Effects of Bacillus subtilis natto on performance and immune function of preweaning calves. Journal of Dairy Science 93(12): 5851-5855.

Windschitl, P. M., Randall, K. M. and Brainard, D. J. (1991). Growth performance of Holstein dairy calves supplemented with a probiotic. Research Progress Report 22.

Zhang, R., Zhou, M., Tu, Y., Zhang, N. F., Deng, K. D., Ma, T. andDiao, Q. Y. (2016). Effect of oral administration of probiotics on growth performance, apparent nutrient digestibility and stress-related indicators in Holstein calves. Journal of Animal Physiology and Animal nutrition, 100(1): 33-38.

\section{How to cite this article:}

Jyotimala Sahu, Saroj Rai, Rajlaxmi Behera, Tripti Kumari, D.K. Mandal and Aayush Yadav. 2019. Economic Analysis of Feeding Synbiotic to Jersey Crossbred Calves. Int.J.Curr.Microbiol.App.Sci. 8(11): 2369-2374. doi: https://doi.org/10.20546/ijcmas.2019.811.274 